Article

\title{
Comparative Study of Two Aging Treatments on Microstructure and Mechanical Properties of an Ultra-Fine Grained Mg-10Y-6Gd-1.5Zn-0.5Zr Alloy
}

\author{
Huan Liu ${ }^{1,3, *} \mathbb{D}^{\mathbb{D}}$, He Huang ${ }^{1}$, Ce Wang ${ }^{1}$, Jia Ju ${ }^{2}$, Jiapeng Sun ${ }^{1}$, Yuna $\mathrm{Wu}^{1}{ }^{1}$, Jinghua Jiang ${ }^{1}$ \\ and Aibin $\mathrm{Ma}^{1, *}$ \\ 1 College of Mechanics and Materials, Hohai University, Nanjing 211100, China; \\ huanghehhu2018@outlook.com (H.H.); wangcehhu2013@outlook.com (C.W.); sunpengp@hhu.edu.cn (J.S.); \\ wuyuna@hhu.edu.cn (Y.W.); jinghua-jiang@hhu.edu.cn (J.J.) \\ 2 College of Materials Engineering, Nanjing Institute of Technology, Nanjing 211167, China; \\ materialju@njit.edu.cn \\ 3 Jiangsu Wujin Stainless Steel Pipe Group Company Limited, Changzhou 213111, China \\ * Correspondence: liuhuanseu@hhu.edu.cn (H.L.); aibin-ma@hhu.edu.cn (A.M.); \\ Tel.: +86-025-8378-7239 (A.M.)
}

Received: 29 July 2018; Accepted: 21 August 2018; Published: 23 August 2018

\begin{abstract}
Developing high strength and high ductility magnesium alloys is an important issue for weight-reduction applications. In this work, we explored the feasibility of manipulating nanosized precipitates on LPSO-contained (long period stacking ordered phase) ultra-fine grained (UFG) magnesium alloy to obtain simultaneously improved strength and ductility. The effect of two aging treatments on microstructures and mechanical properties of an UFG Mg-10Y-6Gd-1.5Zn-0.5Zr alloy was systematically investigated and compared by a series of microstructure characterization techniques and tensile test. The results showed that nano $\gamma^{\prime \prime}$ precipitates were successfully introduced in T5 peak aged alloy with no obvious increase in grain size. While T6 peak aging treatment stimulated the growth of $\alpha-\mathrm{Mg}$ grains to $4.3 \mu \mathrm{m}$ (fine grained, FG), together with the precipitation of $\gamma^{\prime \prime}$ precipitates. Tensile tests revealed that both aging treatments remarkably improved the strengths but impaired the ductility slightly. The T5 peak aged alloy exhibited the optimum mechanical properties with ultimate strength of $431 \mathrm{MPa}$ and elongation of $13.5 \%$. This work provided a novel strategy to simultaneously improve the strength and ductility of magnesium alloys by integrating the intense precipitation strengthening with ductile LPSO-contained UFG/FG microstructure.
\end{abstract}

Keywords: Mg-10Y-6Gd-1.5Zn-0.5Zr; ultra-fine grain; aging treatment; precipitation behavior; mechanical property

\section{Introduction}

Magnesium alloys exhibit great application potential in aerospace, military, transportation and medical equipment industries due to their low density, rich resource and excellent mechanical properties [1]. However, the relatively lower absolute strength and poorer formability of magnesium alloys than that of aluminum alloys restrict their further applications $[2,3]$. Therefore, much attention has been paid in the last few decades to increase the strength and ductility of magnesium alloys via a range of methods such as alloying [4], heat treatment [5,6], plastic deformation [7,8] and so forth.

Among various magnesium alloy series, Mg-RE (Rare earth elements) based alloys always exhibited high-strength as a result of the combination of solid solution strengthening, precipitation strengthening and second phase strengthening [9,10]. The Mg-RE based second phases usually show high hardness and high melting point, thus bearing an important strengthening effect in such magnesium 
alloys [11-13]. Especially, the novel long period stacking ordered (LPSO) phase, which was observed in certain Mg-RE-Zn alloys, exhibited intense strengthening effect (tensile yield strength reaching $600 \mathrm{MPa})[14,15]$. LPSO phase was a both chemical composition ordered and stacking sequence ordered structure and according to the numbers of stacking sequence in a unit cell, the LPSO structure could be diverse [16,17]. Among various types of LPSO structures, 18R and 14H LPSO phases are two commonly observed in Mg-RE-Zn alloys, which contributed to the improved mechanical properties of these alloys [12,18]. At present, lots of efforts have been made to break through the strength limit of magnesium alloys by clarifying the strengthening mechanism of LPSO phase, tailoring the morphology and distribution of LPSO phases and combining LPSO strengthening with other strengthening factors [18-26]. Inspiringly, the introducing of LPSO phase with coherent nano precipitates ( $\beta^{\prime}$ and /or $\gamma^{\prime}$ phase) has been successfully employed in Mg-Y-Zn, Mg-Gd-Zn and Mg-Gd-Y-Zn alloys, which showed enhanced mechanical properties with high strength and moderate elongation $[18,23,24]$.

Grain refinement is another effective method to strengthening metallic materials according to the Hall-Petch relations and it is accepted that metals with ultra-fine grains (UFG) possess a combination of high strength and high ductility [27]. Our previous studies have already proved that the LPSO-containing Mg-RE-Zn alloys with uniform UFG microstructures displayed more excellent ductility than the corresponding rolled or extruded alloys, though the strength was impaired a little $[28,29]$. As is well known, searching for the novel strengthening phases and proposing novel strengthening-toughening strategies are two main ways for new magnesium alloy design [30,31]. Inspired by precipitation strengthening, introducing effective nanosized precipitates with LPSO phases on the good-ductility UFG Mg-RE-Zn alloys might be a breakthrough for novel high-performance magnesium alloys, which was rarely explored in former studies.

Therefore, the main objective of this work was to develop an effective aging treatment on an UFG magnesium alloy to reach simultaneously improved strength and ductility via the combination of fine grain strengthening, precipitation strengthening and LPSO strengthening. To obtain strong age hardening effect, a multi-element Mg-Y-Gd-Zn-Zr alloy was employed. This alloy system has been proved to exhibit obvious aging effect by various precipitates and contains LPSO phase as well, which showed great potential for industrial applications as a promising high-performance magnesium alloy $[23,32,33]$. In the present work, we prepared an UFG Mg-10Y-6Gd-1.5Zn-0.5Zr alloy via multi-pass ECAP first and then comparatively investigated the effects of two kinds of aging treatments (T5 and T6) on precipitation behaviors, microstructure evolutions and mechanical properties of the UFG alloy. Based on above investigations, a high strength and ductility alloy was successfully prepared via the architecture of nanoprecipitates and LPSO phase on UFG/FG grains.

\section{Materials and Methods}

The nominal composition of the studied alloy was Mg-10Y-6Gd-1.5Zn-0.5Zr (wt.\%; denoted as WGZ1061 alloy). The cast alloy ingot was prepared by melting pure $\mathrm{Mg}(99.95 \%)$ and $\mathrm{Zn}(99.95 \%)$ metals and Mg-30Gd (wt.\%), Mg-30Y (wt.\%) and Mg-30Zr (wt.\%) master alloys, in an electric resistance furnace (GR2, Hankou Electric Furnace Co. LTD, Wuhan, China). During heating and subsequent pouring, the system was protected by a mixed atmosphere of $\mathrm{CO}_{2}$ and $\mathrm{SF}_{6}$ with the flow ratio (volume fraction) of 1:99. Then, the WGZ1061 cast alloy was directly subjected to a rotary-die equal channel angular pressing (RD-ECAP) after cutting into cuboid samples with dimension of $20 \mathrm{~mm} \times 20 \mathrm{~mm} \times 45 \mathrm{~mm}$. The schematic diagram of this RD-ECAP, as well as the configuration of ECAP die, could be found in our previous studies [8,34]. For the purpose of successfully fabricating a homogenous UFG alloy, the ECAP temperature was set as $623 \mathrm{~K}$, extrusion speed of $5 \mathrm{~mm} / \mathrm{min}$ and ECAP passes of 16, according to our former experiences [8,29].

Two series of heat treatments, T5 (artificial aging) and T6 (solid solution treatment + artificial aging) were conducted on the UFG alloy, respectively. For T6 treatment, solid solution was performed in a furnace at $673 \mathrm{~K}$ for $2 \mathrm{~h}$. Aging treatment was carried out in an oven at $473 \mathrm{~K}$ for $60 \mathrm{~h}$. 
Vickers microhardness tests of the aged samples with different aging times were performed with an Microhardness Tester (FM700, Future-Tech, Kawasaki, Japan). For each sample, at least five measurements were carried out and the average value was calculated. Then, peak aged alloys (with the highest Vickers hardness values) were selected for further examinations.

The microstructure characterizations of ECAP and aged alloys were analyzed by a scanning electron microscope (SEM, Sirion, FEI Company, Hillsboro, OR, USA) equipped with an X-ray energy dispersive spectrometer (EDS, GENESIS 60S, FEI Company, Hillsboro, OR, USA), an X-ray diffractometer (XRD, D8 DISCOVER, Bruker Corporation, Karlsruhe, Germany) and a transmission electron microscope (TEM, Tecnai $G^{2}$, FEI Company, Hillsboro, OR, USA). The specimens were mechanically ground, polished and etched with $4 \mathrm{~mL}$ nitric acid and $96 \mathrm{~mL}$ ethanol for SEM. Slice samples with thickness of $150 \mu \mathrm{m}$ were twin-jet electron-polished and thinned, using a solution containing 5\% perchloric acid and 95\% ethanol for TEM. To estimate the average grain size of $\alpha-\mathrm{Mg}$ phase and the average diameter of second phase particles, the linear intercept method (ASTM E112-2013) was employed and at least 100 grains and 50 particles were counted. The software of Jade 5.0 was employed to analyze and index the XRD pattern. To evaluate the mechanical properties, room temperature tensile tests of the alloys were conducted by an electronic universal testing machine (CMT5105, MTS, Shenzhen, China) at a tensile speed of $0.2 \mathrm{~mm} / \mathrm{min}$. All deformed and aged samples for tensile specimens exhibited dumbbell shape with the gauge length of $6 \mathrm{~mm}$ and the length direction was parallel to ECAP direction. Moreover, three specimens were employed for each processing state.

\section{Results}

\subsection{Microstructure of As-Cast and ECAP Alloys}

\subsubsection{As-Cast Alloy}

Figure 1 shows the XRD pattern of as-cast WGZ1061 alloy. It can be seen that apart from the $\alpha$-Mg matrix, two kinds of second phases were indexed, binary $\operatorname{Mg}_{24} Y_{5}$-type phase and ternary $\mathrm{Mg}_{12} \mathrm{YZn}$-type phase. $\mathrm{Mg}_{24} \mathrm{Y}_{5}$-type phase is commonly observed in $\mathrm{Mg}$-Y binary alloys or Mg-Y-Zn alloys with higher $\mathrm{Y}$ content [35]. For this alloy, the $\mathrm{Y}$ content is relatively higher than other elements, therefore stimulating the formation of $\mathrm{Mg}_{24} \mathrm{Y}_{5}$-type phase. As for $\mathrm{Mg}_{12} \mathrm{YZn}$-type phase, it was always characterized as a long period stacking ordered (LPSO) phase in Mg-Y-Zn or Mg-Gd-Zn alloys [16,17].

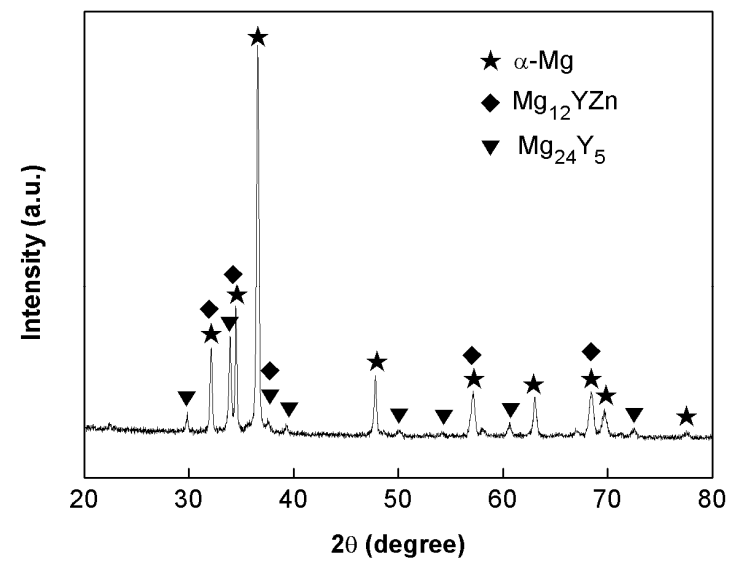

Figure 1. XRD pattern of as-cast Mg-10Y-6Gd-1.5Zn-0.5Zr alloy.

Figure 2a shows the microstructure of as-cast WGZ1061 alloy. It is apparent that $\alpha$-Mg phase exhibited cellular shape with average grain size of $68 \mu \mathrm{m}$. The second phases formed a continuous network, surrounding the cellular $\alpha$-Mg grains. From the enlarged SEM image of Figure $2 b$, three kinds of second phases can be distinguished, as marked by A, B and C. EDS analysis were conducted on 
these regions as well as the $\alpha-\mathrm{Mg}$ matrix (marked by D) and the results were listed in Figure $2 \mathrm{c}-\mathrm{f}$. It can be seen that the main solute elements (Y, Gd and $\mathrm{Zn}$ ) in $\alpha$-Mg matrix (D) is lower than the designed alloy composition. The network phase (A) contains much higher RE elements and its analyzed chemical composition was close to $\mathrm{Mg}_{24}(\mathrm{Y}, \mathrm{Gd}, \mathrm{Zn})_{5}$. Near the network phase, a block phase (B) with lamellar contrast usually located. Apart from the higher $Y$ and Gd elements, it also possessed higher $\mathrm{Zn}$ content and its stoichiometric formula was consistent with $\mathrm{Mg}_{12}(\mathrm{Y}, \mathrm{Gd})_{1} \mathrm{Zn}_{1}$, namely, the LPSO phase. The existence of $\mathrm{Mg}_{24} \mathrm{Y}_{5}$-type phase and LPSO phase will also be demonstrated by later TEM observations. In case of the bright particles that located near the networks or within $\alpha-\mathrm{Mg}$ grains, EDS results suggested that they were Y-rich particles which were ordinary observed in Mg-RE alloys with high Y content [35] and due to the lower volume fraction, they were not identified in XRD pattern. Based on above XRD and SEM observations, it can be concluded that the as-cast WGZ1061 alloy is composed of cellular $\alpha$-Mg grains, network $\mathrm{Mg}_{24}(\mathrm{Y}, \mathrm{Gd}, \mathrm{Zn})_{5}$ phase, 18R-LPSO block phase and a few Y-rich particles. Moreover, the content of $\mathrm{Mg}_{24} \mathrm{Y}_{5}$-type phase was a little higher than that of LPSO phase.

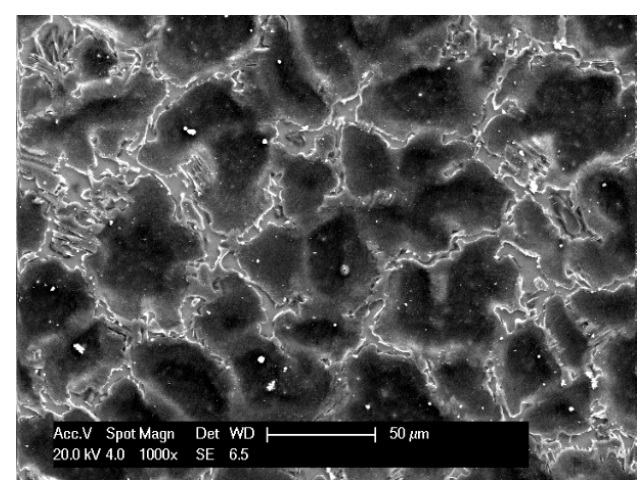

(a)

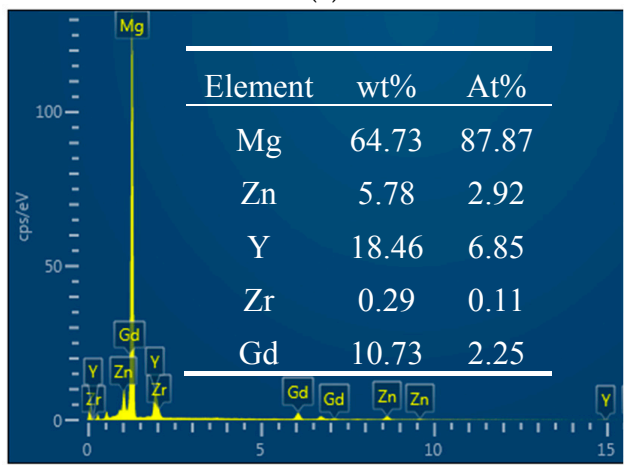

(c)

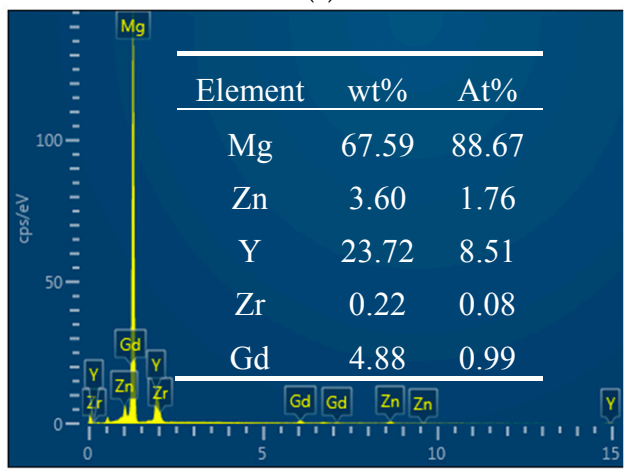

(e)

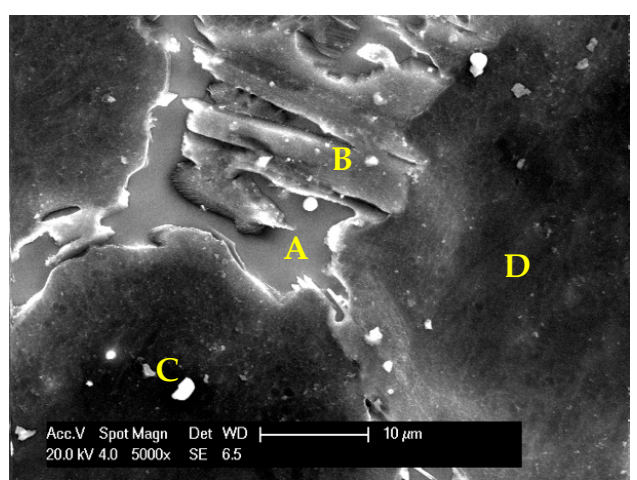

(b)

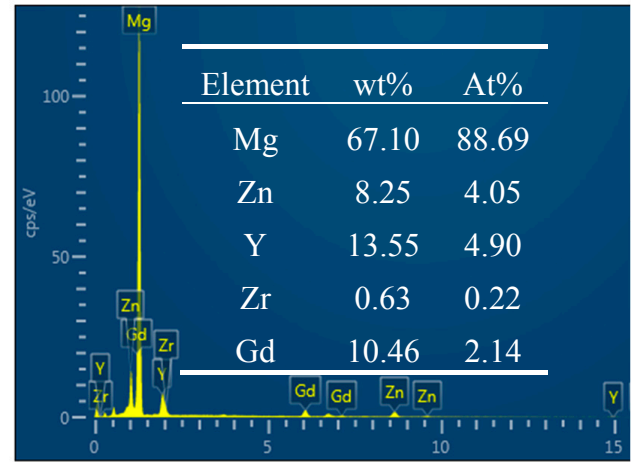

(d)

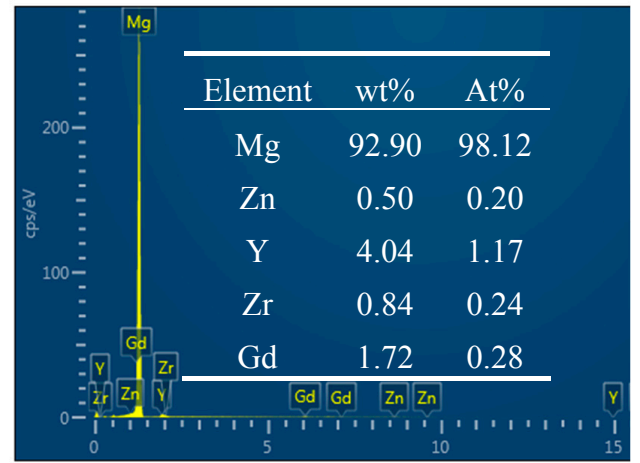

(f)

Figure 2. SEM images of as-cast Mg-10Y-6Gd-1.5Zn-0.5Zr alloy at low (a) and high (b) magnifications and EDS results of areas A (c), B (d), C (e) and D (f) marked in Figure 2b. 


\subsubsection{ECAP Alloy}

Figure 3 shows the microstructure of WGZ1061 alloy after 16 passes of ECAP. The network structure was destroyed during severe plastic deformation and instead, a much-refined microstructure with streamline shape was obtained. In addition, the streamline is parallel to the ECAP punch direction. Seen from the enlarged image of Figure $3 b$, the streamline microstructure could be regarded as a near sandwiched structure with $\alpha-\mathrm{Mg}$ lamellae and second phase lamellae alternately arranged, as marked by the yellow rectangles and blue rectangles, respectively, in Figure 3b. The $\alpha$-Mg lamellae consisted of most fine DRX grains with average grain size of near $1.2 \mu \mathrm{m}$, as is suggested by the statistical histogram inset of Figure 3a. Within the second phase lamellae, both the network $\mathrm{Mg}_{24} \mathrm{Y}_{5}$-type phase and block LPSO phase were crushed, refined and mixed during thermomechanical processing, which will also be demonstrated by later TEM observations. This unique microstructure is consistent with our previous work in Mg-Gd-Zn-Zr alloy [29], demonstrating that microstructure evolutions of this WGZ1061 alloy during multi-pass RD-ECAP was identical to the Mg-Gd-Zn-Zr alloy. Thus, an UFG lamellar structured WGZ1061 alloy was successfully prepared.

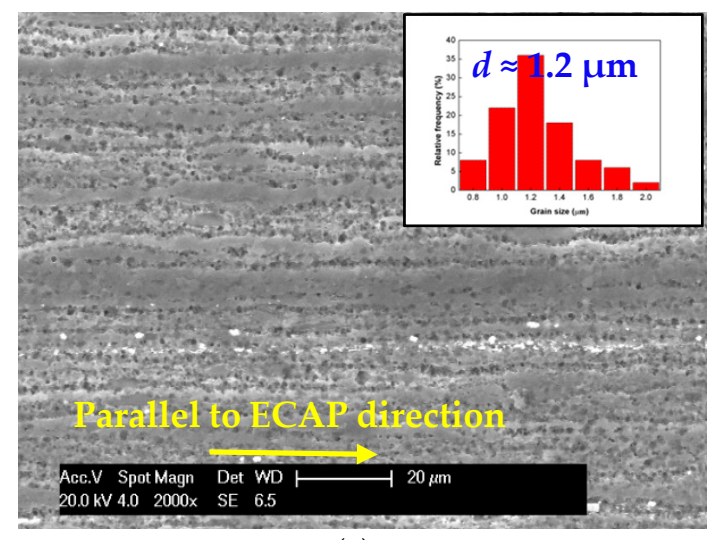

(a)

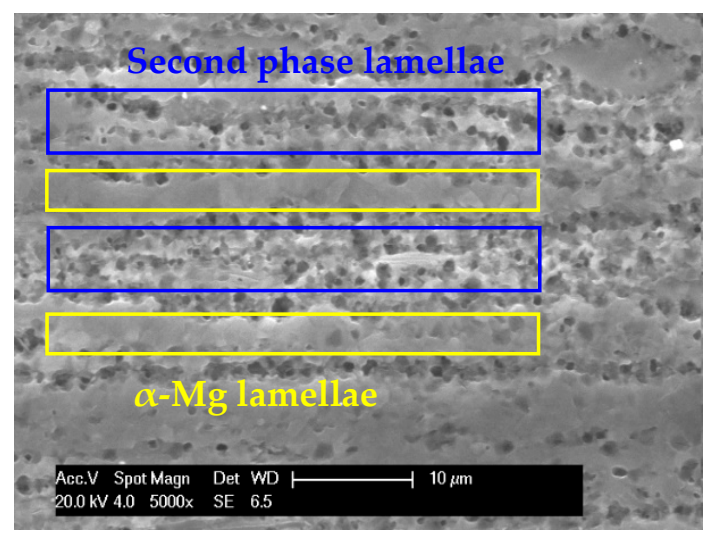

(b)

Figure 3. SEM images of ECAP Mg-10Y-6Gd-1.5Zn-0.5Zr alloy at low (a) and high (b) magnifications (samples were etched with $4 \mathrm{~mL}$ nitric acid and $96 \mathrm{~mL}$ ethanol).

To characterize the UFG microstructure more clearly, TEM observations were conducted on the ECAP alloy. Shown in Figure 4a,b, refined particles with two kinds of morphology could be identified. Marked by yellow arrows, the particles with irregular shape were $\mathrm{Mg}_{24} \mathrm{Y}_{5}$-type phases and the corresponding selected area electron diffraction (SAED) pattern was shown in inset of Figure 4a. The LPSO particles usually exhibited regular shape with smooth boundaries, which was attributed to the special orientation relationship between LPSO phase and $\alpha-\mathrm{Mg}$, generating a coherent interface on (0001) basal plane [17]. Moreover, it can be seen that the two kinds of second phase particles exhibited the same dimensions, ranging from $0.5 \mu \mathrm{m}$ to $1.5 \mu \mathrm{m}$. In addition, DRX grains were also observed in the second phase lamellae, as is shown by red colors in Figure $4 \mathrm{~b}$. Some dark contrasts could also be seen within these DRX grains, suggesting abundant dislocations existed. Figure 4c illustrates a DRX grain surrounded by various fine particles. It is widely accepted that fine hard particles could stimulate the progress of DRX during hot processing via a particle-stimulated nucleation (PSN) manner $[28,36]$ and it is rational to believe that both $\mathrm{Mg}_{24} \mathrm{Y}_{5}$-type particles and LPSO particles could promote DRX during multi-pass ECAP through the so-called PSN mechanism, as the microhardness of them was higher than $\alpha$-Mg phase $[15,18]$. Due to the incompatibility between deformations frequently occurred at the interface between $\alpha$-Mg matrix and the hard particles, a strong stress concentration could be generated around the particles, resulting in the formation of heavily concentrated deformation zones in the Mg grains along the particles. Then, many slip systems must be operated, which could enhance the formation of fine DRX grains [36]. Moreover, these refined particles could also restrict the growth 
of DRX grains during high temperature processing by pinning the grain boundaries. Figure $4 \mathrm{~d}$ shows a typical LPSO particle and its SAED pattern. The index result of the SAED pattern was identical to reported references $[17,18]$ and demonstrated the LPSO phase was $18 \mathrm{R}$ type. Furthermore, we have already detected other LPSO particles in the ECAP alloy and the results showed that almost all LPSO particles were 18R type, $14 \mathrm{H}$-LPSO structure was rarely observed.

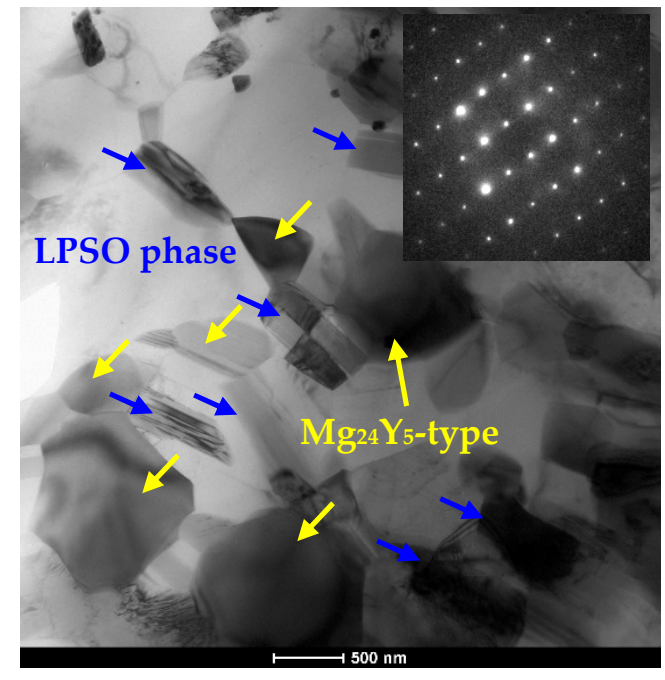

(a)

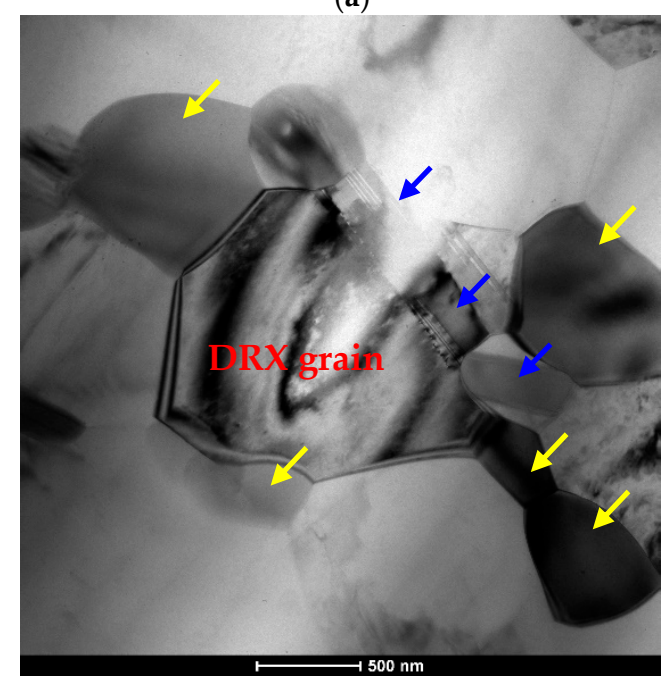

(c)

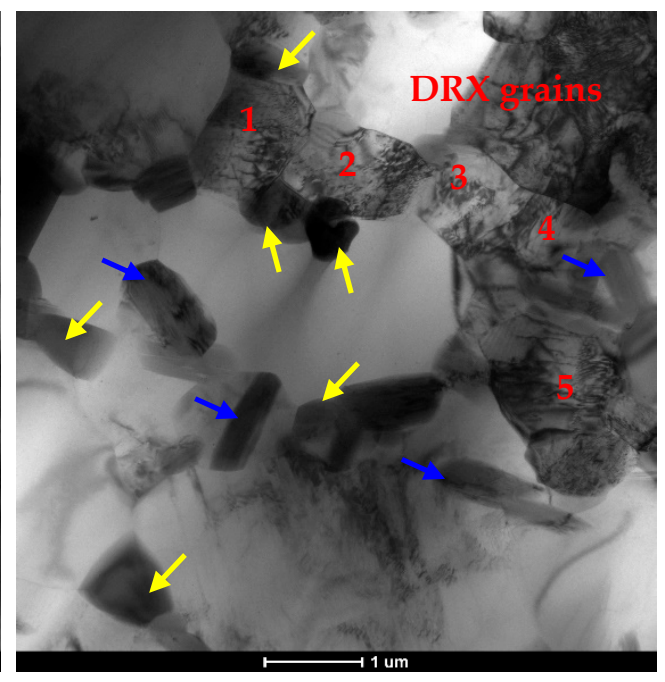

(b)

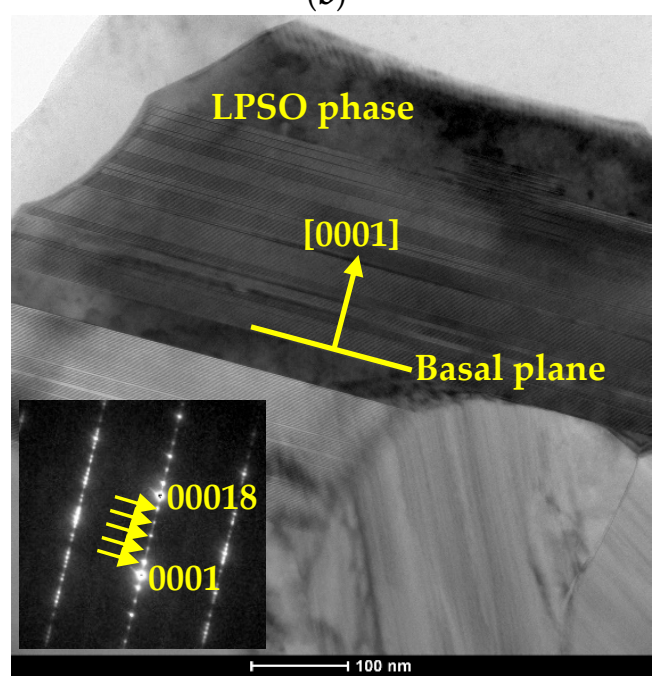

(d)

Figure 4. TEM images of ECAP Mg-10Y-6Gd-1.5Zn-0.5Zr alloy. (a) Distribution of refined second phase particles and inset was the selected area electron diffraction (SAED) pattern of $\mathrm{Mg}_{24} \mathrm{Y}_{5}$-type phase; (b) Mixed region with refined particles and DRX grains; (c) A DRX grain surrounded by various particles; (d) Morphology of 18R-LPSO structure and inset was its SAED pattern.

\subsection{Microstructure of Aged Alloys}

Figure 5 shows the Vickers microhardness variations with aging time of UFG WGZ1061 alloy during two series of aging treatments. The UFG alloy exhibited age hardening response under both T5 and T6 heat treatments. The microhardness increased gradually with aging time, then reached a peak and began to decrease with further prolonged holding time. Under direct artificial aging (T5), the alloy reached its aging peak at $50 \mathrm{~h}$ with highest microhardness of $133 \mathrm{HV}$. As for T6 treatment, owing to the softening effect of anterior solid solution treatment, start of the aging curve was lower but it reached 
the peak faster than T5 curve, with microhardness of $128 \mathrm{HV}$ at aging time of $20 \mathrm{~h}$. Hereafter, T5 $(50 \mathrm{~h})$ and T6 (20 h) alloys in this work represented for the peak aged situations.

Figure $6 a, c$ show the low-magnification SEM images of T5 and T6 alloys, respectively. From the comparison, it is obvious that the microstructure became coarser after T6 heat treatment than T5 treatment, which was mainly ascribed to the relatively high-temperature solution treatment. Although both peak-aged alloys still display lamellar structure, the streamlines of the lamellae turned tortuous, suggesting interaction between $\alpha-\mathrm{Mg}$ lamellae and second phase lamellae took place during aging at moderate temperature. As is illustrated by the statistical histograms inset in Figure $6 \mathrm{~b}, \mathrm{~d}$, the average grain sizes of $\alpha-\mathrm{Mg}$ grains in $\alpha-\mathrm{Mg}$ lamellae were $1.8 \mu \mathrm{m}$ and $4.3 \mu \mathrm{m}$, respectively. In contrast to the ECAP alloy, DRX grains in T5 alloy exhibited no obvious growth, demonstrating that the refined particles with higher melting points are effective to hinder the migration of grain boundaries at the aging temperature of $473 \mathrm{~K}$. However, during T6 treatment, as the former solution treatment was operated at higher temperature of $673 \mathrm{~K}$, which was even higher than the reported critical transformation temperature $(623 \mathrm{~K})$ of LPSO phase [15,37], the migration rate of DRX grain boundaries was accelerated by intense thermal activation and the inhibition effect by fine particles was impaired, thereby DRX grains exhibiting a visible growth to fine grained sizes.

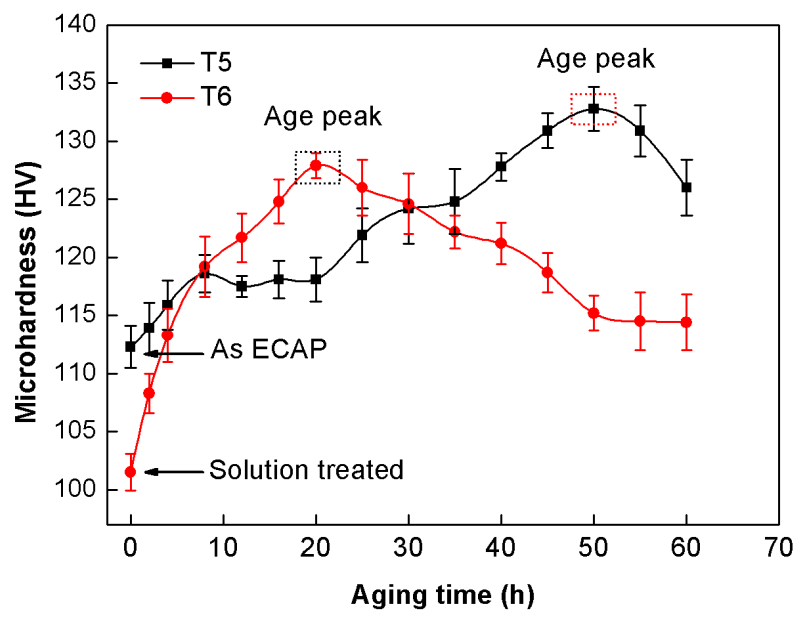

Figure 5. Age hardening curves of ECAP Mg-10Y-6Gd-1.5Zn-0.5Zr alloy for T5 and T6 heat treatments.

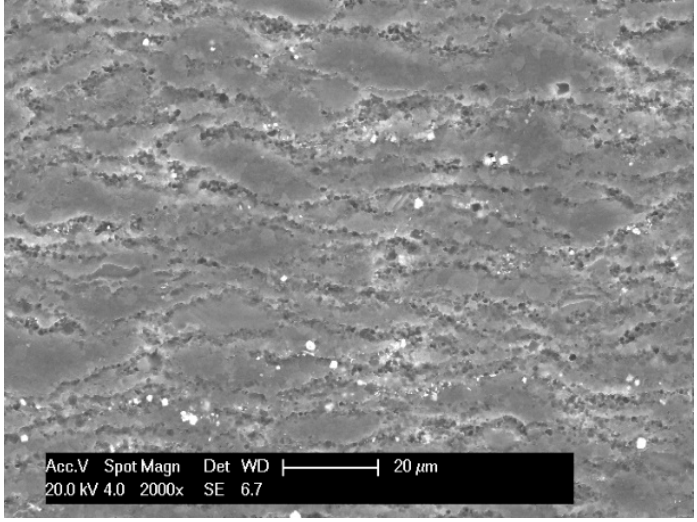

(a)

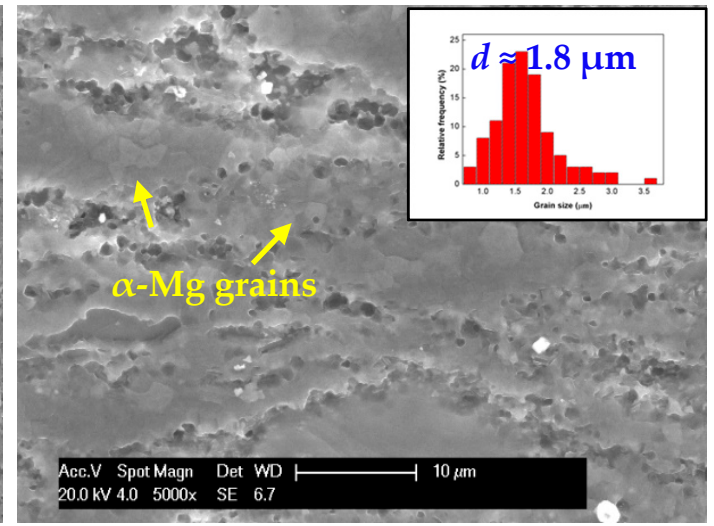

(b)

Figure 6. Cont. 


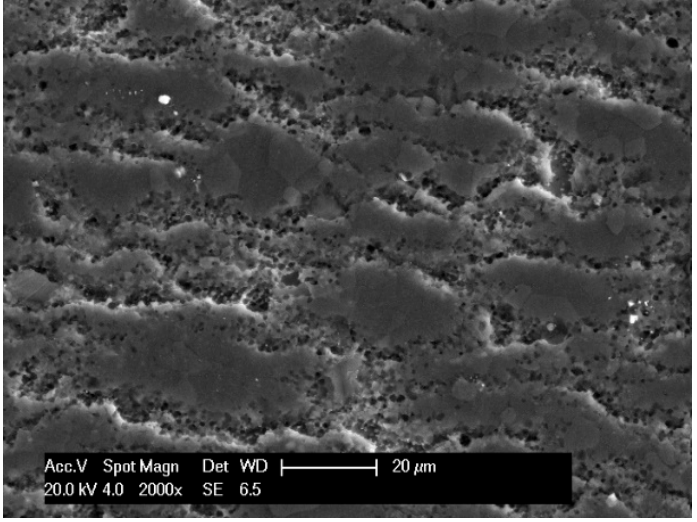

(c)

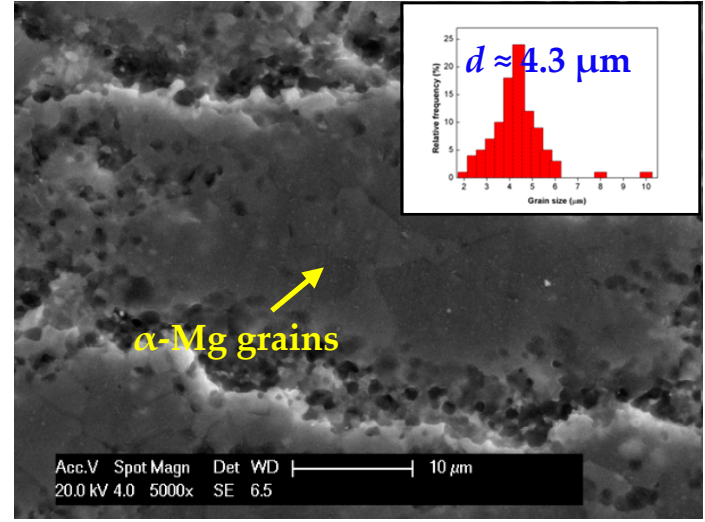

(d)

Figure 6. SEM images of peak aged Mg-10Y-6Gd-1.5Zn-0.5Zr alloys at T5 (a,b) and T6 (c,d) processing states at low $(\mathbf{a}, \mathbf{c})$ and high $(\mathbf{b}, \mathbf{d})$ magnifications (samples were etched with $4 \mathrm{~mL}$ nitric acid and $96 \mathrm{~mL}$ ethanol).

Figure 7 shows the TEM observations of T6 alloy. It can be seen from Figure 7a that abundant fine acicular precipitates with average length of $166 \mathrm{~nm}$ were generated (marked by red arrows). Inset of Figure 7a shows the SAED pattern of these precipitates. No extra diffraction spots were observed but some weak bright lines occurred between the $\alpha$-Mg diffraction spots along [0001] $\alpha$-Mg direction. These diffraction feature demonstrated that the precipitates were $\gamma^{\prime \prime}$ phases, a kind of basal plane precipitates usually observed in Mg-Gd-Zn based alloys [38]. In addition, an enlarged $\gamma^{\prime \prime}$ precipitate is shown in the high-resolution (HR) TEM image of Figure 7b. This precipitate lay on the basal plane of $\alpha-\mathrm{Mg}$, exhibiting a coherent interface. Measurements of this precipitate suggested its length and width were $126.3 \mathrm{~nm}$ and $2.63 \mathrm{~nm}$, respectively. Detailed examination of $\gamma^{\prime \prime}$ precipitates have already been performed and reported in previous studies [38], which exhibited coherent interface with $\alpha-\mathrm{Mg}$ complying with the relationship of $(0001)_{\gamma^{\prime \prime}} / /(0001)_{\alpha}$ and $[1010]_{\gamma^{\prime \prime}} / /[2110]_{\alpha}$.

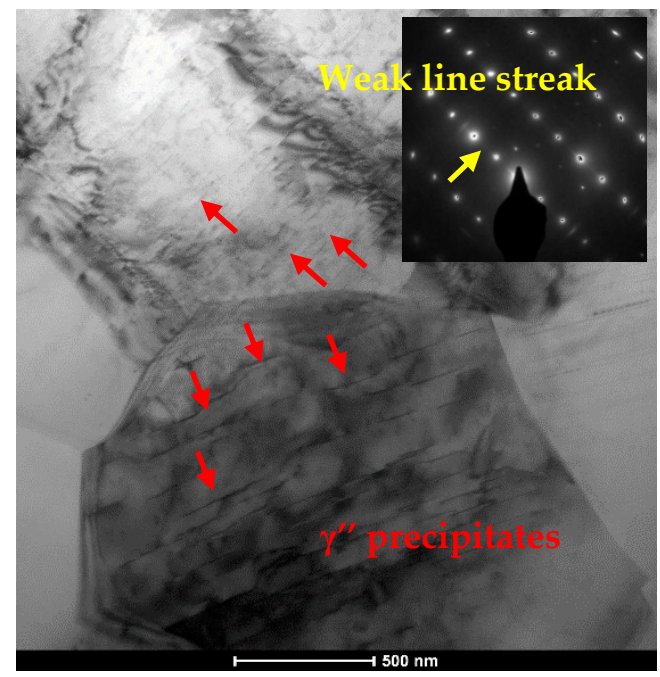

(a)

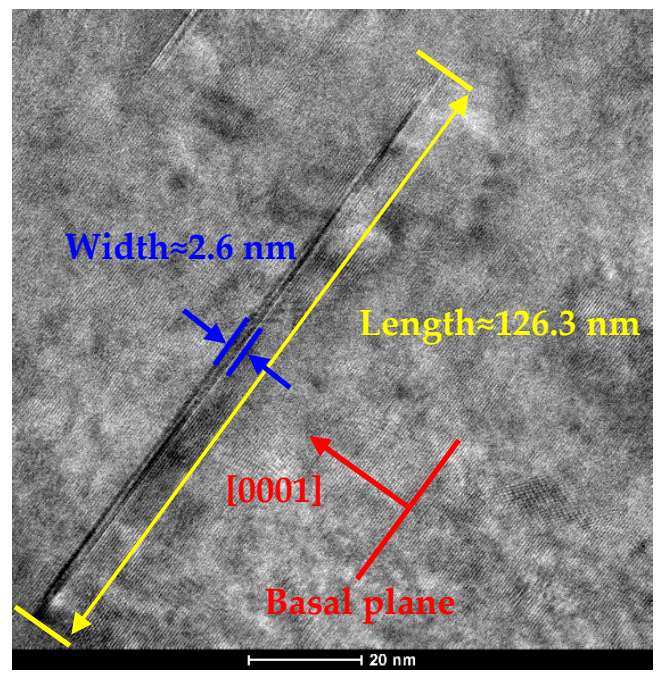

(b)

Figure 7. TEM images of T6 peak aged Mg-10Y-6Gd-1.5Zn-0.5Zr alloy. (a) Acicular $\gamma^{\prime \prime}$ precipitates formed within $\alpha$-Mg grains; (b) High resolution (HR) TEM image of an acicular $\gamma^{\prime \prime}$ precipitate.

Moreover, we also examined the microstructure of T6 over aged alloy to investigate the precipitation behavior. Seen from Figure $8 \mathrm{a}, \gamma^{\prime \prime}$ precipitates grew obviously on the basal plane 
and transformed to $\gamma^{\prime}$ phase, penetrating the whole grain from one side to another [38]. The enlarged $\gamma^{\prime}$ precipitates within one grain and the corresponding SAED patterns were shown in Figure $8 \mathrm{~b}$. The $\gamma^{\prime}$ precipitates exhibited straight line shape and the diffraction brightness (line stream between $\alpha-\mathrm{Mg}$ diffraction spots) became stronger and more obvious than that observed in Figure 7a. Compared with Figure $7 \mathrm{~b}$, the HR-TEM observation of $\gamma^{\prime}$ precipitates in peak aged alloy was also conducted and was listed in Figure 8c. Apart from the increased length, the morphology and width of $\gamma^{\prime}$ precipitates displayed no obvious change with $\gamma^{\prime \prime}$ precipitates, which suggests that $\gamma^{\prime \prime}$ (and/or $\gamma^{\prime}$ ) precipitates preferentially grow along the basal planes. In addition, in the over aged alloy, lamellar 14H-LPSO phases were also detected. Shown in Figure 8d, a kind of lamellar phases existed which were much broader than $\gamma^{\prime}$ precipitates. Inset of the SAED patterns proves they were 14H-LPSO phases, which are easily observed in heat treated $\mathrm{Mg}-\mathrm{Y}-\mathrm{Zn}$ and $\mathrm{Mg}-\mathrm{Gd}-\mathrm{Zn}$ alloys $[17,18]$.

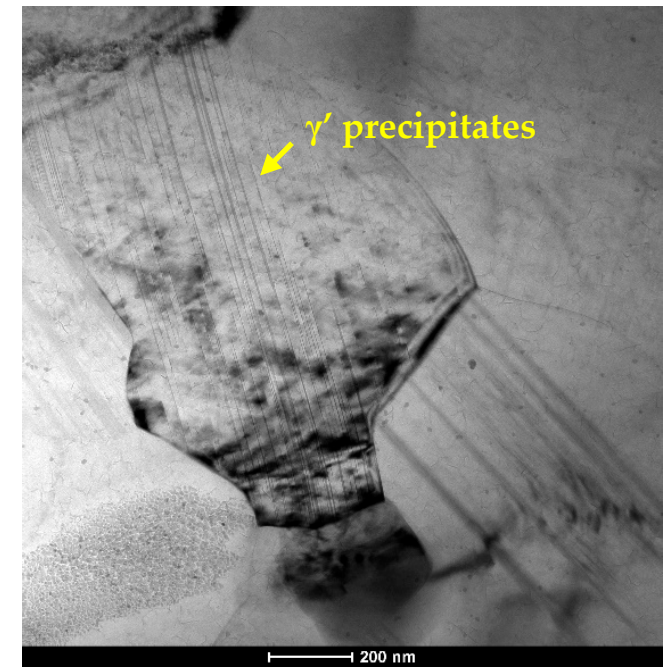

(a)

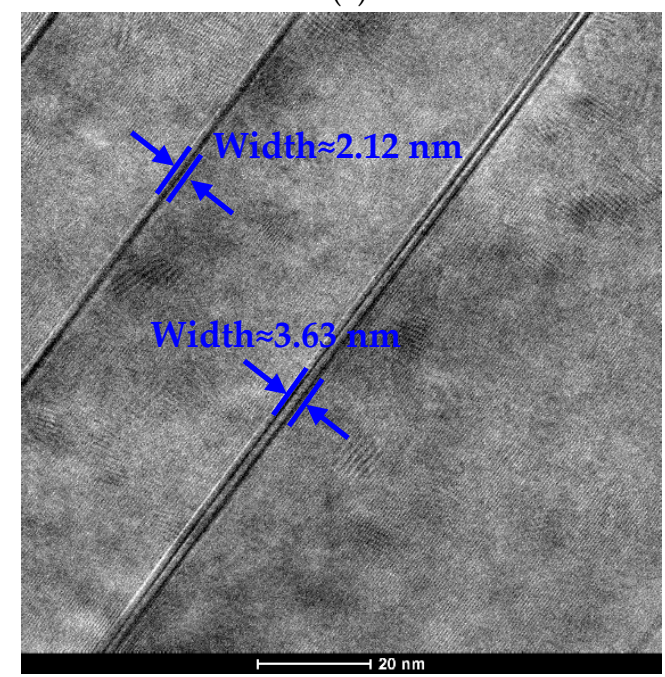

(c)

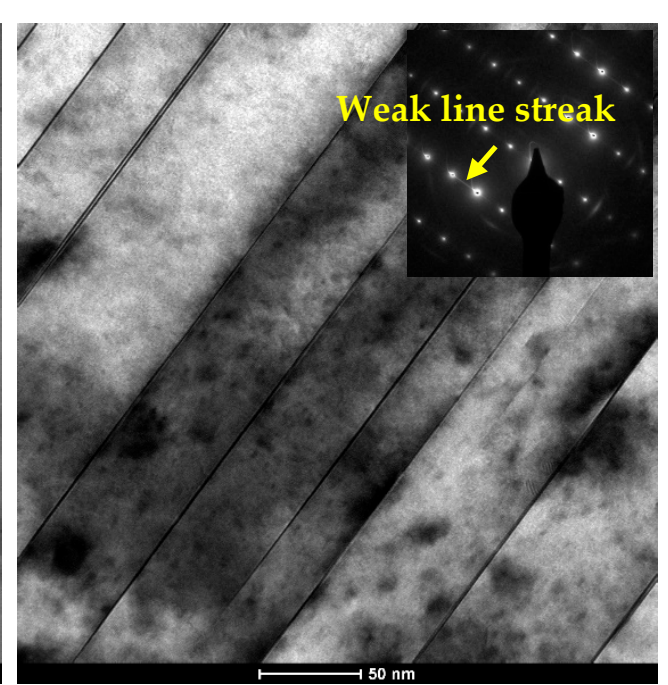

(b)

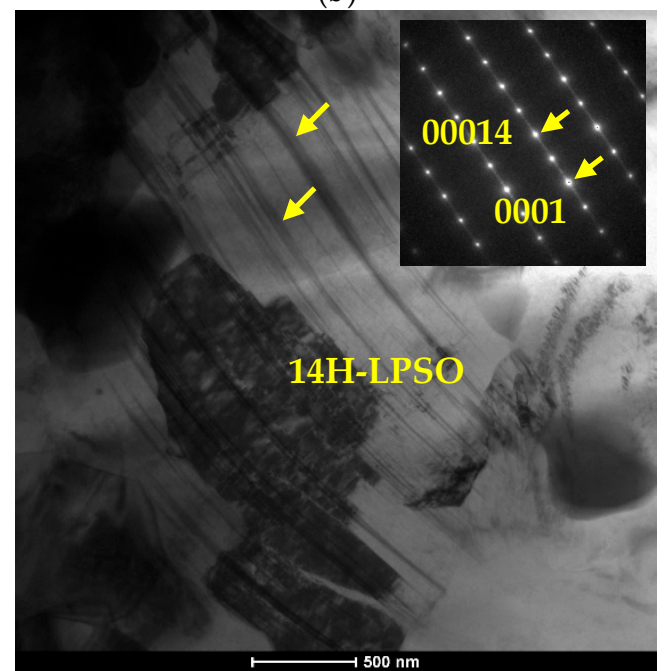

(d)

Figure 8. TEM images of T6 over aged Mg-10Y-6Gd-1.5Zn-0.5Zr alloy. (a) Grown lamellar $\gamma^{\prime}$ precipitates across $\alpha$-Mg grains; (b) Enlargement of the lamellar $\gamma^{\prime}$ precipitates and inset was the corresponding selected area electron diffraction (SAED) pattern; (c) High resolution (HR) TEM image of the lamellar $\gamma^{\prime}$ precipitates; (d) Lamellar 14H-LPSO phase and inset was the corresponding SAED pattern.

Figure 9 shows the TEM observations of T5 peak aged alloy. The same as T6 treated alloy, $\gamma^{\prime \prime}$ precipitates formed during aging, as is shown in Figure 9a. However, the dimensions of these precipitates were much smaller than that observed in T6 peak aged alloy (Figure 7a), which were 
even hard to be distinguished from the SAED pattern (which was not shown here). As marked by red arrows, the length of most $\gamma^{\prime \prime}$ precipitates were shorter than $200 \mathrm{~nm}$, while the average length for T6 peak aged was more than 300 nm (Figure 7a). Furthermore, Figure 9b exhibits the morphology of second phase lamellae in T5 peak aged alloy and it is apparent that both the morphologies and sizes of various particles remained nearly unchanged when compared to ECAP alloy.

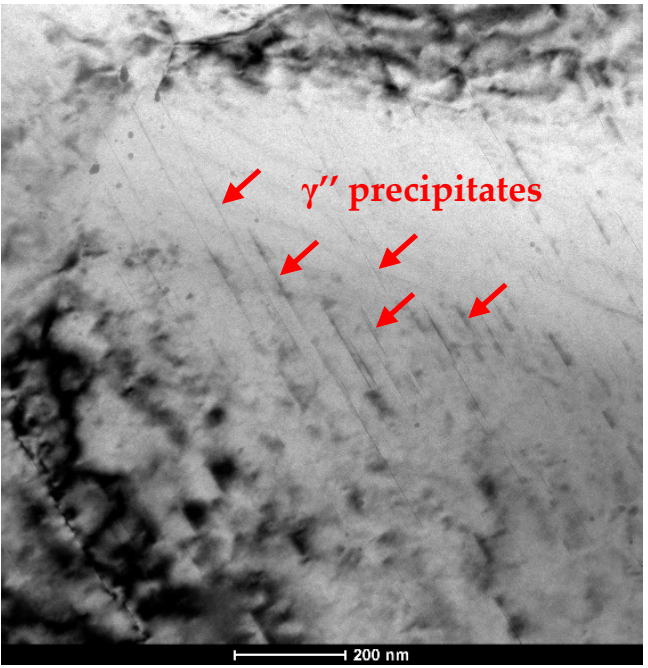

(a)

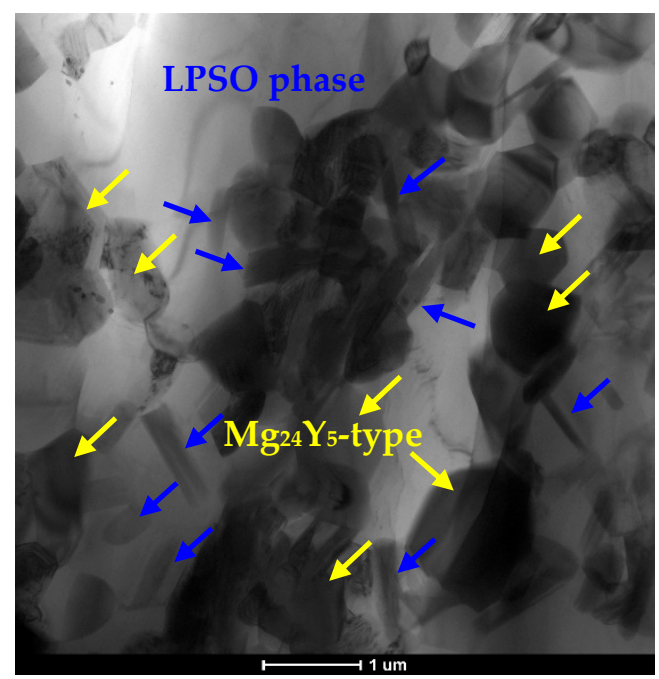

(b)

Figure 9. TEM images of T5 peak aged Mg-10Y-6Gd-1.5Zn-0.5Zr alloy. (a) Nanosized acicular $\gamma^{\prime \prime}$ precipitates in $\alpha$-Mg grain; (b) Morphology of second phase lamellae.

\subsection{Mechanical Properties}

Figure 10 shows the room temperature tensile mechanical properties of WGZ1061 alloys at different processing situations. Compared with as-cast alloy, the ECAP UFG alloy exhibited a remarkable improvement in both strength and ductility. Moreover, after two kinds of peak aging treatments on the UFG alloy, the strength of the alloys was improved further but with minor decrease in elongations. Overall, the T5 peak aged alloy showed the best comprehensive mechanical properties with ultimate tensile strength of $431 \mathrm{MPa}$ and fracture elongation of $13.5 \%$.

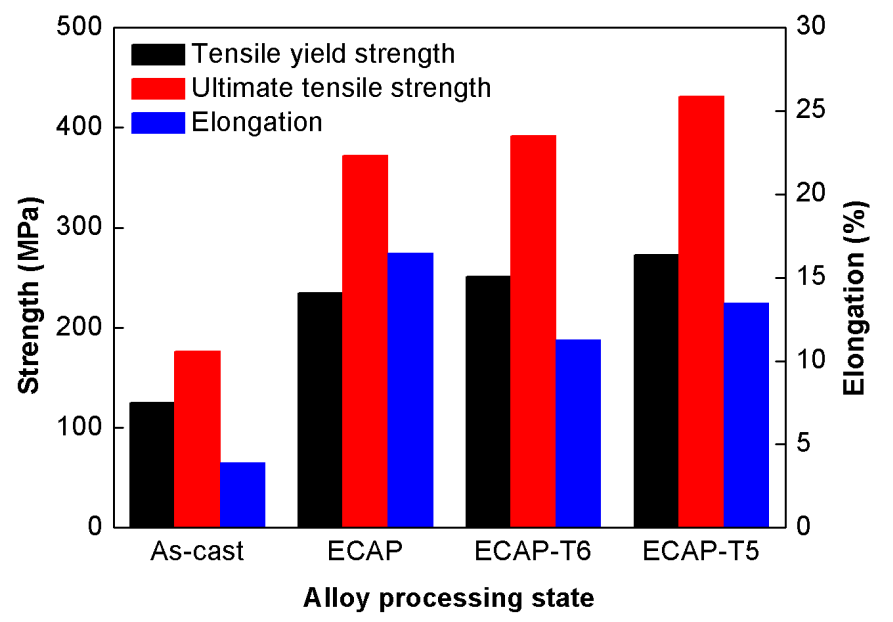

Figure 10. Tensile properties of Mg-10Y-6Gd-1.5Zn-0.5Zr alloys at different processing states. 


\section{Discussion}

\subsection{Precipitation Behavior of UFG Mg-10Y-6Gd-1.5Zn-0.5Zr Alloy}

Table 1 shows the reported precipitation sequences in typical Mg-RE (Gd and Y) based alloys [9,38-43]. For Mg-Y and Mg-Gd binary alloys, precipitation phases formed during isothermal aging were reported to include $\beta^{\prime \prime}, \beta^{\prime}$ and $\beta[39,40]$. The peak aged state usually corresponded to precipitation of $\beta^{\prime}$ phase, which formed as lenticular particles with their broad surface parallel to $\{2110\}_{\alpha-\mathrm{Mg}}[18,39]$. When $\mathrm{Zn}$ element was added to Mg-RE alloys, the situation became more complicated. Apart from the $\beta$ precipitation series, another precipitation series with $\gamma^{\prime \prime}, \gamma^{\prime}$ and $\gamma$ was ordinarily observed [23,38,40]. It was reported that $\gamma^{\prime \prime}$ and $\gamma^{\prime}$ phases were associated with the peak hardness $[23,38]$. High angle annular dark field scanning and transmission electron microscopy (HAADF-STEM) investigations confirmed that the $\gamma^{\prime \prime}$ phase had an ordered hexagonal structure with an ABA stacking sequence of the close-packed planes, while $\gamma^{\prime}$ phase showed an ABCA stacking order of the close-packed planes [38]. Both the two phases exhibited plate-shape, fully coherent with the matrix in the habit (basal) plane and their thickness was often of a single unit cell height but the length of $\gamma^{\prime}$ phase was always larger than $\gamma^{\prime \prime}$ plates. Sometimes, the $\gamma^{\prime}$ plates could extend across the whole grains and were regarded as stacking faults in several former reports [41]. With further increased aging time or temperature, the $\gamma^{\prime}$ phase gradually transformed to $\gamma$ phase, namely, $14 \mathrm{H}$-LPSO phase.

Based on the microstructure observations in this study, the precipitation behavior of the UFG WGZ1061 alloy followed the sequence of $\gamma$ series. As was shown in Figures 7 and 9, the precipitates existed in peak aged alloys were $\gamma^{\prime \prime}$ plates (the $\gamma^{\prime \prime}$ and $\gamma^{\prime}$ precipitates cannot be distinguished clearly in present characterization techniques). While in the over aged alloy, both $\gamma^{\prime}$ precipitates and $\gamma$ (14H-LPSO) phases were developed, which was demonstrated by Figure 8. Moreover, in our previous studies [18], $\beta^{\prime}$ precipitates were commonly observed in both T5 treated and T6 treated Mg-Y-Zn alloy. As for this study, precipitation of $\beta$ series was not detected, which might be ascribed to the addition of Gd element in Mg-Y-Zn alloy that restricted the $\beta^{\prime}$ precipitation under present aging temperature. It has been reported that the composition of $\mathrm{Mg}-\mathrm{Y}-\mathrm{Gd}-\mathrm{Zn}$ alloys greatly influenced the precipitation behaviors during aging, especially the ratio of $Y$ to $G d$ content [9]. However, by not, there was no precise criterion between the $\mathrm{Y} / \mathrm{Gd}$ ratio and precipitation sequences. Therefore, further investigation on the precipitation sequence of various $\mathrm{Mg}-\mathrm{Y}-\mathrm{Gd}-\mathrm{Zn}$ alloys during different aging temperatures and periods need to be carried out, in order to precisely control the microstructure of high performance age-hardenable magnesium alloys. Moreover, Table 2 listed the average sizes and volume fractions of second phase particles in different alloys. Since it is hard to distinguish $\mathrm{Mg}_{24} \mathrm{Y}_{5}$-type phase and LPSO phase particles from the SEM images, the total volume fractions and average sizes of these two-phase particles were estimated. It is apparent that both the size and content of second phase decreased after aging, suggesting these particles were dissolved into the matrix to some extent, which could provide solute atoms for the growth of $\gamma^{\prime \prime}$ precipitates during aging.

Table 1. Comparisons of precipitation sequences in typical Mg-RE based alloys.

\begin{tabular}{cccc}
\hline Alloy Series & Precipitation Sequence & Reference \\
\hline Mg-Y binary alloys & SSSS $\rightarrow$ G.P. $\rightarrow \beta^{\prime \prime}\left(\mathrm{D0}_{19}\right) \rightarrow \beta^{\prime}\left(\mathrm{Mg}_{7} \mathrm{Y}\right) \rightarrow \beta\left(\mathrm{Mg}_{24} \mathrm{Y}_{5}\right)$ & {$[39]$} \\
\hline Mg-Gd binary alloys & SSSS $\rightarrow$ G.P. $\rightarrow \beta^{\prime \prime}\left(\mathrm{D0}_{19}\right) \rightarrow \beta^{\prime}\left(\mathrm{Mg}_{7} \mathrm{Gd}\right) \rightarrow \beta_{1}\left(\mathrm{Mg}_{3} \mathrm{Gd}\right) \rightarrow \beta\left(\mathrm{Mg}_{5} \mathrm{Gd}\right)$ & {$[40]$} \\
\hline & $\mathrm{SSSS} \rightarrow \beta_{1}\left(\mathrm{Mg}_{3} \mathrm{Gd}\right) \rightarrow \beta\left(\mathrm{Mg}_{5} \mathrm{Gd}\right)$ & {$[41]$} \\
Mg-Gd-Zn alloys & $\mathrm{SSSS} \rightarrow \mathrm{SF}(\rightarrow 14 \mathrm{H} \mathrm{LPSO})$ & {$[41]$} & {$[38]$} \\
\hline Mg-Y-Zn alloys & $\mathrm{SSSS} \rightarrow \gamma^{\prime \prime}\left(\mathrm{Mg}_{70} \mathrm{Gd}_{15} \mathrm{Zn}_{15}\right) \rightarrow \gamma^{\prime}(\mathrm{MgGdZn}) \rightarrow \gamma(14 \mathrm{H} \mathrm{LPSO})$ & {$[41,43]$} \\
\hline
\end{tabular}


Table 2. Measurements of average $\alpha$-Mg grain size, average size and volume fraction of second phase particles in alloys with different processing situations.

\begin{tabular}{cccc}
\hline Processing States & $\begin{array}{c}\text { Average } \boldsymbol{\alpha} \text {-Mg Grain } \\
\text { Size }(\boldsymbol{\mu m})\end{array}$ & $\begin{array}{c}\text { Average Particle Size } \\
(\boldsymbol{\mu \mathbf { m } )}\end{array}$ & $\begin{array}{c}\text { Volume Fraction of } \\
\text { Particles (\%) }\end{array}$ \\
\hline As-cast & $68 \pm 9.7$ & - & $\sim 33 \%$ \\
ECAP & $1.24 \pm 0.26$ & $0.89 \pm 0.28$ & $\sim 28 \%$ \\
ECAP-T5 & $1.83 \pm 0.47$ & $0.83 \pm 0.30$ & $\sim 26 \%$ \\
ECAP-T6 & $4.30 \pm 1.02$ & $0.70 \pm 0.25$ & $\sim 22 \%$ \\
\hline
\end{tabular}

\subsection{Relationship between the Microstructure and Mechanical Properties}

The relatively poor mechanical property of cast alloy could be ascribed to the coarse network structure, as well as the existed casting defects such as micro-voids or segregations. After multi-pass ECAP, most of the casting defects were diminished and a UFG microstructured alloy was obtained. Owing to the fine grain (grain boundary) strengthening, dislocations strengthening and fine second phase (LPSO phase and $\mathrm{Mg}_{24} \mathrm{Y}_{5}$-type phase particles) strengthening, strength of the alloy was significantly enhanced compared to cast alloy. Moreover, its ductility was also improved, which mainly resulted from the increased numbers and probability of activated dislocations slip systems due to the refined and randomly orientated DRX grains [27]. Moreover, the refined and homogenous microstructure could also accommodate deformations during tensile test. After further two kinds of aging treatments, both T5 and T6 peak aged alloys displayed higher strength than ECAP alloy. Although the $\alpha$-Mg grain sizes in peak aged alloys increased, their strengths were often higher than the untreated alloys as the precipitation strengthening played an important role in strengthening of these alloys. However, due to the increased grain size and the obstacle of precipitates on dislocations slips, the ductility of aged alloys was impaired to some extent, which was in accordance with the regular rules of precipitation on mechanical properties of metallic alloys [18,23].

However, it is worth noting that the strength T6 peak aged alloy was lower than T5 treated alloy. This could be explained by the microstructure evolutions, especially the changes of grain sizes and volume fractions of second phase particles shown in Table 2. On the one hand, the $\alpha$-Mg grains in T6 alloy $(4.3 \mu \mathrm{m})$ were much larger than T5 alloy $(1.8 \mu \mathrm{m})$, which was mainly ascribed to the pre-solution treatment of T6 at $673 \mathrm{~K}$ and grains grew at higher thermal activation. Therefore, the effect of fine grain strengthening was weakened for T6 alloy. On the other hand, the generated $\gamma^{\prime \prime}$ precipitates in T5 alloy were much finer than that in T6 peak aged alloy and the average distances between precipitates were estimated to be $36 \mathrm{~nm}$ and $91 \mathrm{~nm}$ for $\mathrm{T} 5$ and T6 alloys, respectively. As a consequence, these fine precipitates with smaller distances are more effective in strengthening the alloy according to the Orowan mechanism [23]. In addition, as a result of the finer grain size for T5 alloy than T6 alloy, T5 alloy showed better ductility. As was demonstrated by this study, the strengthening effect of these nanosized precipitates constructed on the toughening LPSO-contained UFG/FG alloy showed great potential with simultaneously enhanced strength and ductility. However, seen from Figure 9a, the distribution of fine $\gamma^{\prime \prime}$ precipitates was not uniformly arranged within all grains and its density could be further improved. The growth of UFG grains during aging should also be considered and restrained for better ductility. Therefore, it is rational to believe that with proper design of heat treatment and deformation, alloys with optimal combination of strength and ductility could be developed based on the establishment of UFG grains, UFG LPSO and/or Mg-RE particles and nanosized precipitates and our future work will emphasize on this viewpoint.

\section{Conclusions}

(1) The as-cast WGZ1061 alloy was composed of $\alpha$-Mg matrix, network-shaped $\mathrm{Mg}_{24} \mathrm{Y}_{5}$-type phase, block LPSO phase and a few Y-rich particles. After sixteen passes of ECAP, the UFG microstructure with alternately arranged $\alpha-\mathrm{Mg}$ lamellae and second phase lamellae was obtained. 
(2) The UFG WGZ1061 alloy exhibited obvious age hardening effects during two aging treatments. The average grain size increased form $1.2 \mu \mathrm{m}$ to $4.3 \mu \mathrm{m}$ after T6 peak aging and abundant nanosized $\gamma^{\prime \prime}$ plates were precipitated. With further over aging, $\gamma^{\prime \prime}$ phases were gradually transformed to $\gamma^{\prime}$ plates and 14H-LPSO lamellae. In T5 peak aged situation, the grain sizes of $\alpha$-Mg changed not obviously and abundant finer $\gamma^{\prime \prime}$ plates were generated.

(3) Both T5 and T6 aging treatments significantly promoted the strength of the ECAP alloy, together with slight decreases in ductility. The T5 peak aged alloy exhibited the superior comprehensive mechanical properties with ultimate strength of $431 \mathrm{MPa}$ and elongation of $13.5 \%$, suggesting great application potential and feasibility of manipulating nanosized precipitates on LPSO-contained UFG magnesium alloy. In future studies, the detailed precipitation sequences and their influences on UFG/FG Mg-RE-Zn alloys shall be investigated.

Author Contributions: H.L. and A.M. conceived and designed the experiments; H.H., C.W. and J.J. (Jia Ju) performed the experiments; J.S. and Y.W. analyzed the data; H.L. and J.J. (Jinghua Jiang) wrote the paper. All authors have discussed the results, read and approved the final manuscript.

Funding: This work was funded by the Natural Science Foundation of Jiangsu Province of China (grant number BK20160869), the Fundamental Research Funds for the Central Universities (grant number 2018B16614), the Natural Science Foundation of China (grant number 51774109) and the China Postdoctoral Science Foundation (grant number 2017M611671).

Acknowledgments: The author and coauthors would like to thank Jing Bai and Yue Zhang at Southeast University for their assistance in the sample preparation and microstructure analysis.

Conflicts of Interest: The authors declare no conflict of interest.

\section{References}

1. Wang, X.J.; Xu, D.K.; Wu, R.Z.; Chen, X.B.; Peng, Q.M.; Jin, L.; Xin, Y.C.; Zhang, Z.Q.; Liu, Y.; Chen, X.H.; et al. What is going on in magnesium alloys? J. Mater. Sci. Technol. 2018, 34, 245-247. [CrossRef]

2. Feng, B.; Xin, Y.C.; Guo, F.L.; Yu, H.H.; Wu, Y.; Liu, Q. Compressive mechanical behavior of Al/Mg composite rods with different types of Al sleeve. Acta Mater. 2016, 120, 379-390. [CrossRef]

3. Yu, H.H.; Li, C.; Xin, Y.C.; Chapuis, A.; Huang, X.X.; Liu, Q. The mechanism for the high dependence of the Hall-Petch slope for twinning/slip on texture in Mg alloys. Acta Mater. 2017, 128, 313-326. [CrossRef]

4. Pan, F.S.; Yang, M.B.; Chen, X.H. A review on casting magnesium alloys: Modification of commercial alloys and development of new alloys. J. Mater. Sci. Technol. 2016, 32, 1211-1221. [CrossRef]

5. Wei, J.; Huang, G.H.; Yin, D.D.; Li, K.N.; Wang, Q.D.; Zhou, H. Effects of ECAP and annealing treatment on the microstructure and mechanical properties of Mg-1Y (wt.\%) binary alloy. Metals 2017, 7, 119. [CrossRef]

6. Liu, H.; Bai, J.; Yan, K.; Yan, J.L.; Ma, A.B.; Jiang, J.H. Comparative studies on evolution behaviors of $14 \mathrm{H}$ LPSO precipitates in as-cast and as-extruded Mg-Y-Zn alloys during annealing at $773 \mathrm{~K}$. Mater. Des. 2016, 93, 9-18. [CrossRef]

7. Pan, H.C.; Ren, Y.P.; Fu, H.; Zhou, H.; Wang, L.Q.; Meng, X.Y.; Qin, G.W. Recent developments in rare-earth free wrought magnesium alloys having high strength: A review. J. Alloys Compd. 2016, 663, 321-331. [CrossRef]

8. Liu, H.; Ju, J.; Bai, J.; Sun, J.P.; Song, D.; Yan, J.L.; Jiang, J.H.; Ma, A.B. Preparation, microstructure evolutions, and mechanical property of an ultra-fine grained Mg-10Gd-4Y-1.5Zn-0.5Zr alloy. Metals 2017, 7, 398. [CrossRef]

9. Nie, J.F. Precipitation and hardening in magnesium alloys. Metall. Mater. Trans. A 2012, 43, 3891-3939. [CrossRef]

10. Chiu, C.; Liu, H.C. Mechanical properties and corrosion behavior of WZ73 Mg Alloy/SiC $\mathrm{p}$ composite fabricated by stir casting method. Metals 2018, 8, 424. [CrossRef]

11. Xu, D.K.; Han, E.H.; Xu, Y.B. Effect of long-period stacking ordered phase on microstructure, mechanical property and corrosion resistance of Mg alloys: A review. Prog. Nat. Sci. Mater. Int. 2016, 26, 117-128. [CrossRef]

12. Shao, X.H.; Yang, Z.Q.; Ma, X.L. Strengthening and toughening mechanisms in Mg-Zn-Y alloy with a long period stacking ordered structure. Acta Mater. 2010, 58, 4760-4771. [CrossRef] 
13. Tekumalla, S.; Seetharaman, S.; Almajid, A.; Gupta, M. Mechanical properties of magnesium-rare earth alloy systems: A review. Metals 2015, 5, 1-39. [CrossRef]

14. Kawamura, Y.; Hayashi, K.; Inoue, A.; Masumoto, T. Rapidly solidified powder metallurgy $\mathrm{Mg}_{97} \mathrm{Zn}_{1} \mathrm{Y}_{2}$ alloys with excellent tensile yield strength above $600 \mathrm{MPa}$. Mater. Trans. 2001, 42, 1172-1176. [CrossRef]

15. Itoi, T.; Seimiya, T.; Kawamura, Y.; Hirohashi, M. Long period stacking structures observed in $\mathrm{Mg}_{97} \mathrm{Zn}_{1} \mathrm{Y}_{2}$ alloy. Scr. Mater. 2004, 51, 107-111. [CrossRef]

16. Zhu, Y.M.; Morton, A.J.; Nie, J.F. Growth and transformation mechanisms of $18 \mathrm{R}$ and $14 \mathrm{H}$ in Mg-Y-Zn alloys. Acta Mater. 2012, 60, 6562-6572. [CrossRef]

17. Zhu, Y.M.; Morton, A.J.; Nie, J.F. The $18 \mathrm{R}$ and $14 \mathrm{H}$ long-period stacking ordered structures in Mg-Y-Zn alloys. Acta Mater. 2010, 58, 2936-2947. [CrossRef]

18. Liu, H.; Xue, F.; Bai, J.; Sun, Y.S. Effect of heat treatments on the microstructure and mechanical properties of an extruded $\mathrm{Mg}_{95.5} \mathrm{Y}_{3} \mathrm{Zn}_{1.5}$ alloy. Mater. Sci. Eng. A 2013, 585, 261-267. [CrossRef]

19. Yamasaki, M.; Hashimoto, K.; Hagihara, K.; Kawamura, Y. Effect of multimodal microstructure evolution on mechanical properties of Mg-Zn-Y extruded alloy. Acta Mater. 2011, 59, 3646-3658. [CrossRef]

20. Liu, W.; Zhang, J.S.; Wei, L.Y.; Xu, C.X.; Zong, X.M.; Hao, J.Q. Extensive dynamic recrystallized grains at kink boundary of $14 \mathrm{H}$ LPSO phase in extruded $\mathrm{Mg}_{92} \mathrm{Gd}_{3} \mathrm{Zn}_{1} \mathrm{Li}_{4}$ alloy. Mater. Sci. Eng. A 2017, 681, 97-102. [CrossRef]

21. Liu, X.; Zhang, Z.Q.; Hu, W.Y.; Le, Q.C.; Bao, L.; Cui, J.Z. Effects of extrusion speed on the microstructure and mechanical properties of Mg-9Gd-3Y-1.5Zn-0.8Zr alloy. J. Mater. Sci. Technol. 2016, 32, 313-319. [CrossRef]

22. Xu, C.; Nakata, T.; Qiao, X.G.; Zheng, M.Y.; Wu, K.; Kamado, S. Effect of LPSO and SFs on microstructure evolution and mechanical properties of Mg-Gd-Y-Zn-Zr alloy. Sci. Rep. 2017, 7, 40846. [CrossRef] [PubMed]

23. Xu, C.; Nakata, T.; Qiao, X.G.; Zheng, M.Y.; Wu, K.; Kamado, S. Ageing behavior of extruded Mg-8.2Gd-3.8Y-1.0Zn-0.4Zr (wt.\%) alloy containing LPSO phase and $\gamma^{\prime}$ precipitates. Sci. Rep. 2017, 7, 43391. [CrossRef] [PubMed]

24. Rong, W.; Wu, Y.J.; Zhang, Y.; Sun, M.; Chen, J.; Peng, L.M.; Ding, W.J. Characterization and strengthening effects of $\gamma^{\prime}$ precipitates in a high-strength casting Mg-15Gd-1Zn-0.4Zr (wt.\%) alloy. Mater. Charact. 2017, 126, 1-9. [CrossRef]

25. Lapovok, R.; Gao, X.; Nie, J.F.; Estrin, Y.; Mathaudhu, S.N. Enhancement of properties in cast Mg-Y-Zn rod processed by severe plastic deformation. Mater. Sci. Eng. A 2014, 615, 198-207. [CrossRef]

26. Yu, Z.J.; Huang, Y.D.; Mendis, C.L.; Hort, N.; Meng, J. Microstructural evolution and mechanical properties of Mg-11Gd-4.5Y-1Nd-1.5Zn-0.5Zr alloy prepared via pre-ageing and hot extrusion. Mater. Sci. Eng. A 2015, 624, 23-31. [CrossRef]

27. Valiev, R.Z.; Longdon, T.G. Principles of equal-channel angular pressing as a processing tool for grain refinement. Prog. Mater. Sci. 2006, 7, 881-981. [CrossRef]

28. Liu, H.; Ju, J.; Yang, X.W.; Yan, J.L.; Song, D.; Jiang, J.H.; Ma, A.B. A two-step dynamic recrystallization induced by LPSO phases and its impact on mechanical property of severe plastic deformation processed $\mathrm{Mg}_{97} \mathrm{Y}_{2} \mathrm{Zn}_{1}$ alloy. J. Alloys Compd. 2017, 704, 509-517. [CrossRef]

29. Lu, F.M.; Ma, A.B.; Jiang, J.H.; Yang, D.H.; Yuan, Y.C.; Zhang, L.Y. Formation of profuse long period stacking ordered microcells in Mg-Gd-Zn-Zr alloy during multipass ECAP process. J. Alloys Compd. 2014, 601, 140-145. [CrossRef]

30. Zeng, Z.R.; Nie, J.F.; Xu, S.W.; Davies, C.H.J.; Birbilis, N. Super-formable pure magnesium at room temperature. Nat. Commun. 2017, 8, 972. [CrossRef] [PubMed]

31. Trang, T.T.T.; Zhang, J.H.; Kim, J.H.; Zargaran, A.; Hwang, J.H.; Suh, B.C.; Kim, N.J. Designing a magnesium alloy with high strength and high formability. Nat. Commun. 2018, 9, 2522. [CrossRef] [PubMed]

32. Sun, W.T.; Xu, C.; Qiao, X.G.; Zheng, M.Y.; Kamado, S.; Gao, N.; Starink, M.J. Evolution of microstructure and mechanical properties of an as-cast $\mathrm{Mg}-8.2 \mathrm{Gd}-3.8 \mathrm{Y}-1.0 \mathrm{Zn}-0.4 \mathrm{Zr}$ alloy processed by high pressure torsion. Mater. Sci. Eng. A 2017, 700, 312-320. [CrossRef]

33. Yu, Z.J.; Xu, C.; Meng, J.; Zhang, X.H.; Kamado, S. Effects of pre-annealing on microstructure and mechanical properties of as-extruded Mg-Gd-Y-Zn-Zr alloy. J. Alloys Compd. 2017, 729, 627-637. [CrossRef]

34. Liu, H.; Cheng, Z.J.; Yan, K.; Yan, J.L.; Bai, J.; Jiang, J.H.; Ma, A.B. Effect of multi-pass equal channel angular pressing on the microstructure and mechanical properties of a heterogeneous $\mathrm{Mg}_{88} \mathrm{Y}_{8} \mathrm{Zn}_{4}$ alloy. J. Mater. Sci. Technol. 2016, 32, 1274-1281. [CrossRef] 
35. Zhang, L.; Zhang, J.H.; Leng, Z.; Liu, S.J.; Yang, Q.; Wu, R.Z.; Zhang, M.L. Microstructure and mechanical properties of high-performance Mg-Y-Er-Zn extruded alloy. Mater. Des. 2014, 54, 256-263. [CrossRef]

36. Hagihara, K.; Kinoshita, A.; Sugino, Y.; Yamasaki, M.; Kawamura, Y.; Yasuda, H.Y.; Umakoshi, Y. Effect of long-period stacking ordered phase on mechanical properties of Mg97Zn1Y2 extruded alloy. Acta Mater. 2010, 58, 6282-6293. [CrossRef]

37. Kawamura, Y.; Yamasaki, M. Formation and mechanical properties of $\mathrm{Mg}_{97} \mathrm{Zn}_{1} \mathrm{RE}_{2}$ alloys with long-period stacking ordered structure. Mater. Trans. 2007, 48, 2986-2992. [CrossRef]

38. Nie, J.F.; Oh-ishi, K.; Gao, X.; Hono, K. Solute segregation and precipitation in a creep-resistant Mg-Gd-Zn alloy. Acta Mater. 2008, 56, 6061-6076. [CrossRef]

39. Nishijima, M.; Yubuta, K.; Hiraga, K. Characterization of $\beta^{\prime}$ precipitate phase in $\mathrm{Mg}-2 \mathrm{at} \%$ Y alloy aged to peak hardness condition by high-angle annular detector dark-field scanning transmission electron microscopy (HAADF-STEM). Mater. Trans. 2007, 48, 84-87. [CrossRef]

40. Nishijima, M.; Hiraga, K. Structural changes of precipitates in an Mg-5 at $\%$ Gd alloy studied by transmission electron microscopy. Mater. Trans. 2007, 48, 10-15. [CrossRef]

41. Yamasaki, M.; Sasaki, M.; Nishijima, M.; Hiraga, K.; Kawamura, Y. Formation of $14 \mathrm{H}$ long period stacking ordered structure and profuse stacking faults in $\mathrm{Mg}-\mathrm{Zn}-\mathrm{Gd}$ alloys during isothermal aging at high temperature. Acta Mater. 2007, 55, 6798-6805. [CrossRef]

42. Zhu, Y.M.; Morton, A.J.; Weyland, M.; Nie, J.F. Characterization of planar features in Mg-Y-Zn alloys. Acta Mater. 2010, 58, 464-475. [CrossRef]

43. Zhu, Y.M.; Weyland, M.; Morton, A.J.; Oh-ishi, K.; Hono, K.; Nie, J.F. The building block of long-period structures in Mg-RE-Zn alloys. Sci. Mater. 2009, 60, 980-983. [CrossRef]

(C) 2018 by the authors. Licensee MDPI, Basel, Switzerland. This article is an open access article distributed under the terms and conditions of the Creative Commons Attribution (CC BY) license (http://creativecommons.org/licenses/by/4.0/). 